\title{
Micro Fluidic Channel Machining on Fused Silica Glass Using Powder Blasting
}

\author{
Ho-Su Jang ${ }^{1}$, Myeong-Woo Cho ${ }^{2}$ and Dong-Sam Park ${ }^{1, *}$ \\ 1 Department of Mechanical Engineering, University of Incheon, Incheon 402-749, Korea \\ E-mail: dspark@incheon.ac.kr
}

2 Division of Mechanical Engineering, Inha University, Incheon 402-751, Korea

E-mail:kdw525@gmail.com,E-mail: chomwnet@inha.ac.kr

* Author to whom correspondence should be addressed.

Received: 14 January 2008 / Accepted: 29 January 2008 / Published: 6 February 2008

\begin{abstract}
In this study, micro fluid channels are machined on fused silica glass via powder blasting, a mechanical etching process, and the machining characteristics of the channels are experimentally evaluated. In the process, material removal is performed by the collision of micro abrasives injected by highly compressed air on to the target surface. This approach can be characterized as an integration of brittle mode machining based on micro crack propagation. Fused silica glass, a high purity synthetic amorphous silicon dioxide, is selected as a workpiece material. It has a very low thermal expansion coefficient and excellent optical qualities and exceptional transmittance over a wide spectral range, especially in the ultraviolet range. The powder blasting process parameters affecting the machined results are injection pressure, abrasive particle size and density, stand-off distance, number of nozzle scanning, and shape/size of the required patterns. In this study, the influence of the number of nozzle scanning, abrasive particle size, and pattern size on the formation of micro channels is investigated. Machined shapes and surface roughness are measured using a 3-dimensional vision profiler and the results are discussed.
\end{abstract}

Keywords: Micro powder blasting, Fused silica glass, Micro Fluidic channel, Fuel cell, Lab-on-a- chip, Bio sensor.

\section{Introduction}

Micro fluidic channel fabrication technologies play a key role in many of today's industrial areas, including the energy and bio technology fields where they are employed in the fabrication of micro 
fuel cells and biochips with higher efficiency. Commonly required technological features of such products are size miniaturization, multi-functional structure, and power consumption reduction. In the near future, it will be necessary to manufacture such products with higher efficiency, greater precision, and smaller size.[1 5] To achieve these goals, it is important to develop more competitive micro structure fabrication technologies that offer advantages in cost, time, and flexibility. Chemical etching processes have been widely used to fabricate micro structures and/or patterns. However, chemical etching may lead to undesired undercutting or overetching due to solution density or reaction time variation, and it is carried out in a harmful environment.

Thus, in this study, a powder blasting method, a type of mechanical etching process, is applied for micro fluidic channel fabrication. In the process, material removal is performed by the collision of micro abrasives injected by highly compressed air on to the target surface. This approach can be characterized as an integration of brittle mode machining based on micro crack propagation.[6 9] Fused silica glass, which is a high purity synthetic amorphous silicon dioxide $\left(\mathrm{SiO}_{2}\right)$, is used as a target material for micro channel fabrication. It has a very low thermal expansion coefficient with excellent optical qualities and exceptional transmittance over a wide spectral range, especially in the ultraviolet range. It can be used for biochips, lenses, and prisms in a transmission range of $0.16 \mu \mathrm{m}$ to $3 \mu \mathrm{m}$. Micro channels are machined on fused silica glass via a powder blasting method and their characteristics are experimentally evaluated. In the process, process parameters such as injection pressure, abrasive particle size and density, stand-off distance and scanning times of the nozzle, and patterns shapes and size affect the machined results. [10 13] In this study, the influence of the number of nozzle scanning, abrasive particle size, and pattern size on the pattern formation is investigated. Machined shapes and surface roughness are measured using a 3-dimensional vision profiler and the results are discussed.

Table 1. Mechanical properties of fused silica glass.

\begin{tabular}{ll}
\hline \multicolumn{1}{c}{ Parameter } & \multicolumn{1}{c}{ Standard } \\
\hline Density & $2.201 \mathrm{~g} / \mathrm{cm}^{3}$ \\
Shear Modulus & $31 \mathrm{GPa}$ at $25^{\circ} \mathrm{C}$ \\
Young's Modulus & $73 \mathrm{GPa}$ at $25^{\circ} \mathrm{C}$ \\
Tensile Strength & $50 \mathrm{MPa}$ \\
Compressive Strength & $1.1 \mathrm{GPa}$ \\
Knoop Hardness & $500 \mathrm{~kg} / \mathrm{mm}^{2}$ \\
\hline
\end{tabular}

\section{Material Properties of Fused Silica Glass}

Fused silica glass is a high purity synthetic amorphous silicon dioxide $\left(\mathrm{SiO}_{2}\right)$. It can be obtained by electric arc melting high purity sand deposits at extremely high temperature (above $2000^{\circ} \mathrm{C}$ ). It has a highly cross linked 3-dimensional structure. This noncrystalline, colorless, silica glass combines a very low thermal expansion coefficient with excellent optical qualities and exceptional transmittance over a wide spectral range, especially in the ultraviolet. It is resistant to scratching and thermal shock. Fused silica glass can be used for different applications and is available with various grades. One of its important applications is high energy laser optics. No other optical material matches the purity of fused silica, and therefore its ability to withstand and transmit high energy laser pulses with limited absorption or damage to the material is similarly unrivaled. Fused silica glass can also be used for biochips, lenses, and prisms in a transmission range of $0.16 \mu \mathrm{m}$ to $3 \mu \mathrm{m}$. Its refractive index varies from 
1.55 to 1.40 through the transmission range. Material properties of the used fused silica glass are presented in Tables 1 and 2.

Table 2. Thermal properties of fused silica glass.

\begin{tabular}{ll}
\hline \multicolumn{1}{c}{ Parameter } & \multicolumn{1}{c}{ Standard } \\
\hline Specific Heat Capacity & $703 \mathrm{~J} / \mathrm{Kg} \mathrm{K}$ \\
Coefficient of Expansion & $0.55 \times 10^{-6} /{ }^{\circ} \mathrm{C}$ \\
Softening Point & $1600^{\circ} \mathrm{C}$ \\
Strain Point & $1025^{\circ} \mathrm{C}$ \\
Melting Point & $1713^{\circ} \mathrm{C}$ \\
\hline
\end{tabular}

\section{Basic principles of the Powder Blasting}

In the powder blasting process, micro abrasives (tens of $\mu \mathrm{m}$ ), accelerated by highly compressed air or gases, are forced through a ceramic nozzle, and collide with a workpiece at a very high velocity (80 $-200 \mathrm{~m} / \mathrm{s}$ ) and density. The nozzle can be moved along the X- and Y-directions to scan surface areas. The workpiece is covered with a patterned mask; thus, the open areas of the workpiece are removed by the injected abrasive particles. Since the material removal process of powder blasting is performed by a type of brittle mode machining based on micro crack propagation, there is very little heat, chipping, or crack generation in the workpiece. Thus, this method is suitable for the machining of micro shapes (such as grooves, holes, pockets, etc.) of hard and brittle materials (such as glass, ceramics, silicon, crystal, etc.). A rebounded mixture of abrasives and chips from the workpiece is sent to the distributor, which then separates the mixture into chips and abrasives for recycling.

The process parameters of powder blasting are: (1) blasting pressure, time, and velocity; (2) material properties, size and density of the abrasives; (3) velocity and number of nozzle scanning; and (4) stand-off distance (distance between the nozzle and workpiece). These parameters should be appropriately determined to improve machining accuracy and efficiency. The basic principle of the machining process is illustrated in Figure 1.
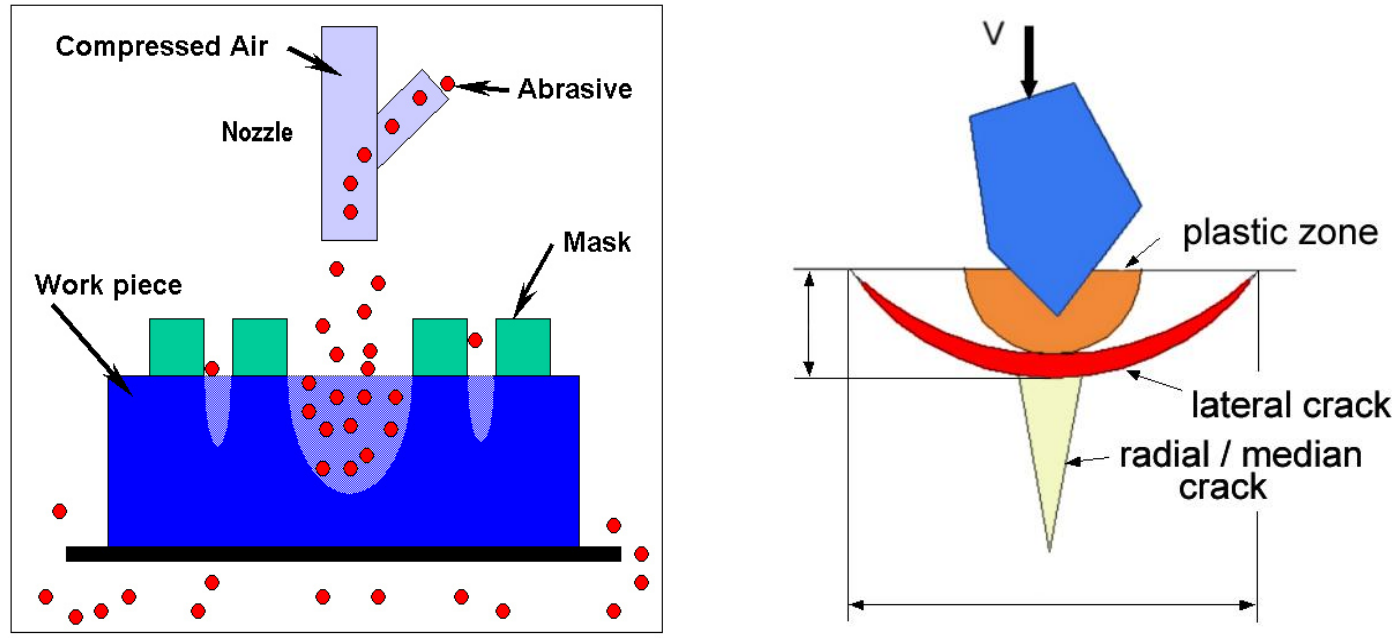

Figure 1. Basic material removal mechanism of powder blasting. 


\section{Experimental Methods}

\subsection{Specimen Preparation}

The process flow of the micro channel fabrication process using powder blasting is illustrated in Figure 2. The procedure can be described as follows.

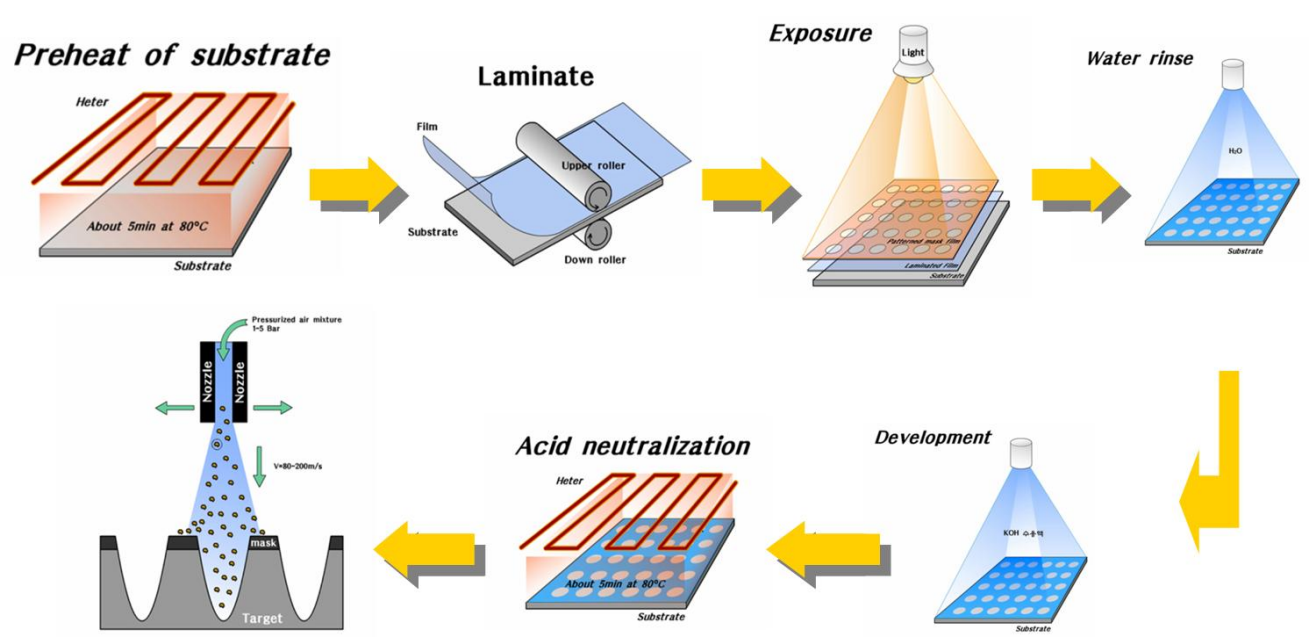

Figure 2. Patterning process by powder blasting.

Micro pattern design: Figure 3(a) shows the details of the designed micro patterns and micro channels; square and circular patterns are designed for biochip application. Two types of patterns are designed: $200 \mu \mathrm{m}$ channels $(\mathrm{W}=200 \mu \mathrm{m}, \mathrm{A}=\mathrm{D}=400 \mu \mathrm{m}$ and $\mathrm{L}=8 \mathrm{~mm})$ and $300 \mu \mathrm{m}$ channels ( $\mathrm{W}=300 \mu \mathrm{m}, \mathrm{A}=\mathrm{D}=600 \mu \mathrm{m}$ and $\mathrm{L}=8 \mathrm{~mm}$ ). These patterns are used for the masking process.

Masking process: The purpose of the masking process is to prepare required specimens with micro patterns. A dry film is used for the masking process. The film thickness influences the resolution and accuracy of the machined shapes. UV hardening polyurethane is used as a film material to provide wear-resistance during the process. The details of the applied masking process are as follows:

- Laminating: A film is adhered to the workpiece.

- Exposure: A parallel UV beam is irradiated to make required patterns.

- Developing: The specimen is developed using a developing solution, which is composed of distilled water and a $5 \% \mathrm{Na}_{2} \mathrm{CO}_{3}$ solution. Finally, required patterns can be obtained by removing the masks from the desired regions.

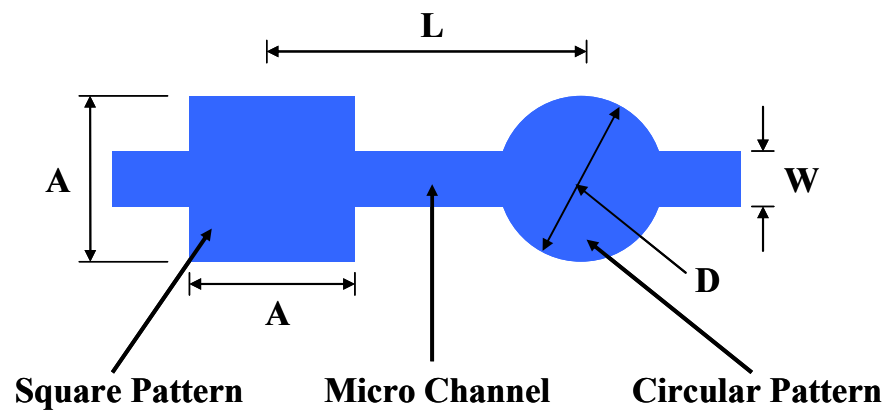

(a) Detail of designed patterns.

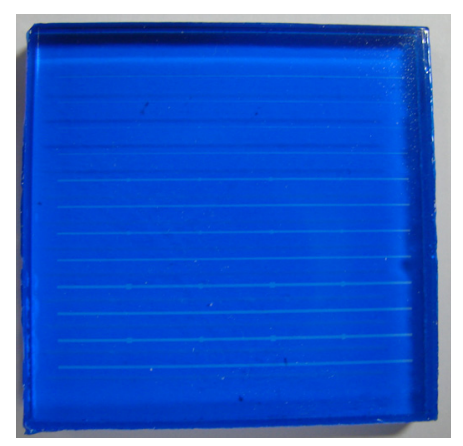

(b) Photograph of masked pattern.

Figure 3. Designed pattern and masked specimen. 

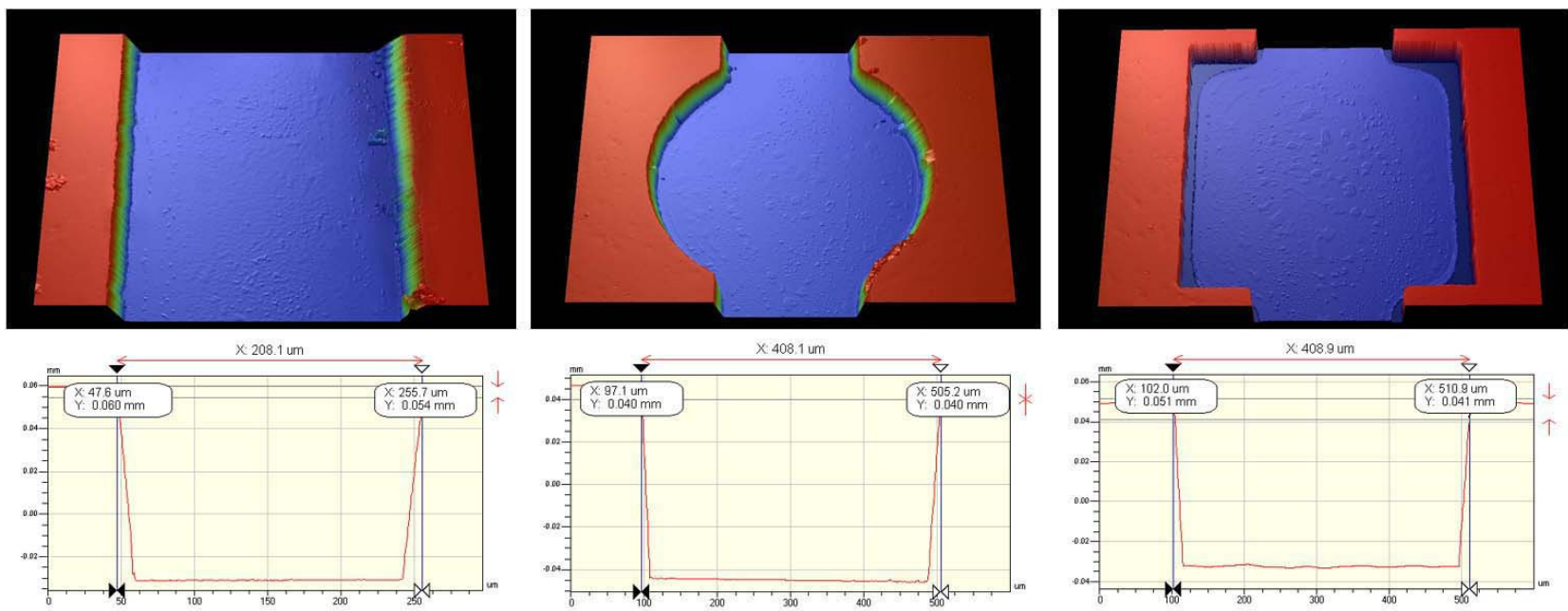

(a) $200 \mu \mathrm{m}$ channels (groove, circular and square patterns).
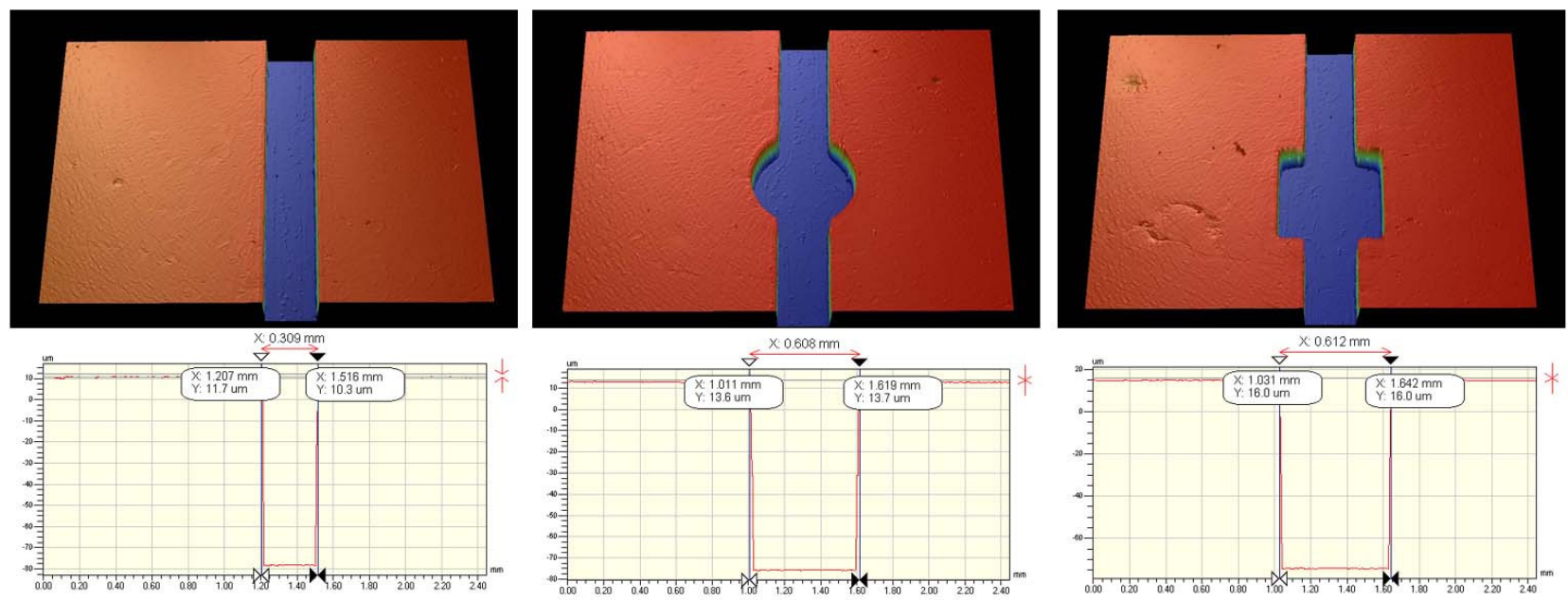

(b) $300 \mu \mathrm{m}$ channels (groove, circular and square patterns).

Figure 4. 3-dimensional shapes and cross-sectional profiles of masked patterns.

(vertical scale $=20 \mu \mathrm{m}$, horizontal scale $=50 \mu \mathrm{m})$

Figure 3(b) shows a photograph of a specimen after the masking process. Figure 4 shows measured 3-dimensional shapes and cross-sectional profiles of the masks formed on the glass. From the results, it is found that the measured width of the masked pattern is about $10 \mu \mathrm{m}$ larger than the designed value. This discrepancy is attributed to errors such as resolution difference, light dispersion in the exposure process, etc.

Powder blasting process: Powder blasting is performed on the machine. Here, the regions from which the masks are removed in the developing process are selectively machined.

Mask removing and cleaning process: After the machining process is finished, any remaining mask adhering to the workpiece surface is removed, and the workpiece is cleaned using ultrasonic cleaning equipment. 


\subsection{Abrasive Particles}

Two types of abrasives, WA\#600 and \#1200, are used for the micro powder blasting experiments. WA denotes white alundum, and its main ingredient is $\mathrm{Al}_{2} \mathrm{O}_{3}$. Figure 5 shows $\mathrm{SEM}$ micrographs of the employed abrasive particles.

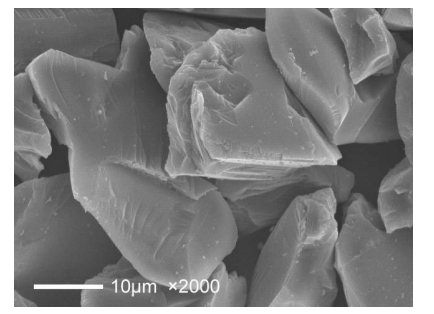

(a) WA\#600
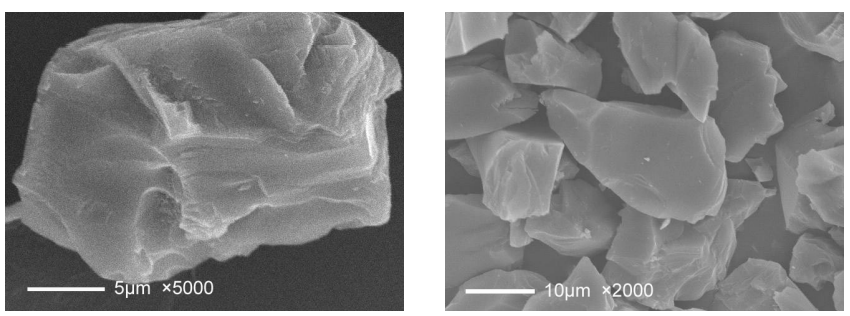

(b) WA\#1200

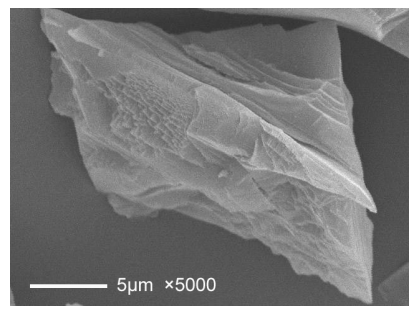

Figure 5. SEM micrographs of used abrasive particles.

\subsection{Experimental Conditions}

All experiments in this study are performed using MICROBLASTER (type MB1, Japan), which has a ceramic injection nozzle with an $8 \mathrm{~mm}$ inner diameter. After powder blasting, the machined pattern shapes are measured and investigated using a 3-dimensional measuring device (WYCO NT-2000) and SEM (Jeol JSM-5200 scanning microscope).

Table 4. Experimental conditions for powder blasting.

\begin{tabular}{cc}
\hline Powder material & WA\#600, WA\#1200 \\
Impact angle & $90^{\circ}$ \\
Scanning speed & $100 \mathrm{~mm} / \mathrm{sec}$ \\
Abrasive mass flow rate & $100 \mathrm{~g} / \mathrm{min}$ \\
Blasting pressure & $0.15 \mathrm{MPa}$ \\
Scanning counts & $5,10,15,20$ \\
\hline
\end{tabular}

\section{Experimental Results}

Figure 6 and 7 show the machined results of $200 \mu \mathrm{m}$ channels obtained under the experimental conditions listed in Table 4. Formed pattern shapes are measured using WYCO NT-2000 and WYCO Vision32. From the figure, it can be observed that the groove shapes are formed very well, and have U-shape cross-sections due to the material removal characteristics of the applied powder blasting method. 

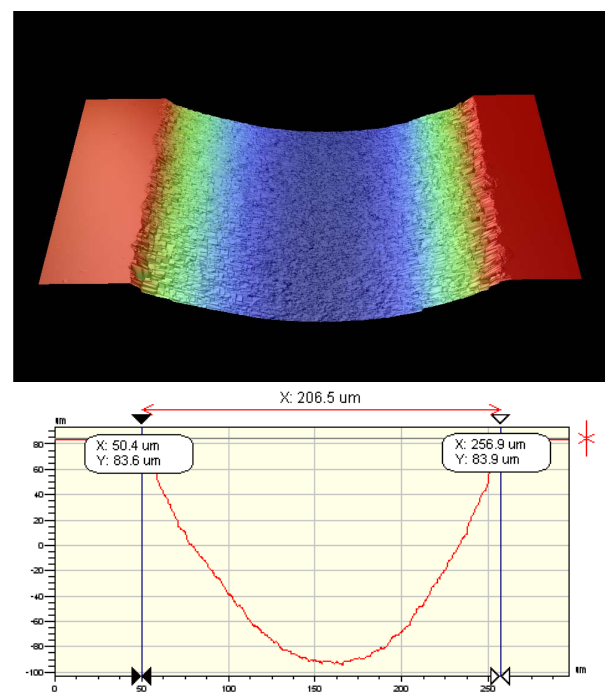

(a) Channel (20 scanning)
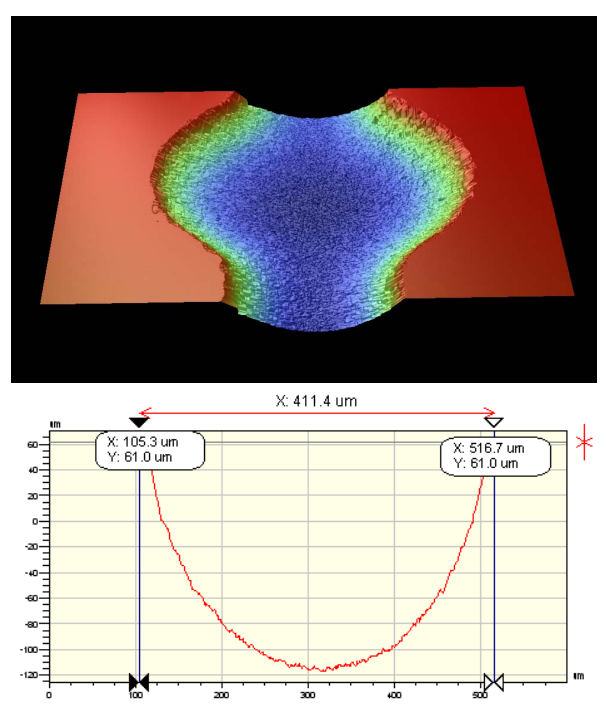

(b) Circle (20 scanning)
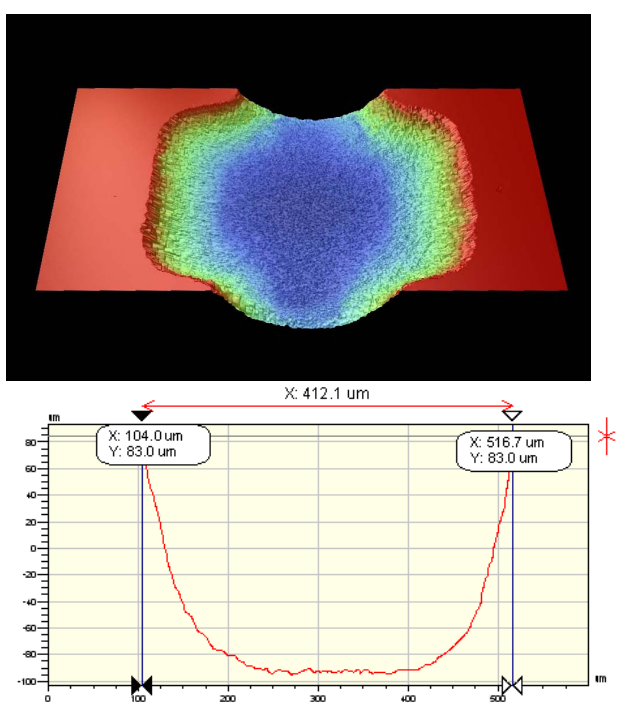

(c) Square (20 scanning)

Figure 6. 3-dimensional shapes and cross-sectional profiles of $200 \mu \mathrm{m}$ channels using WA\#600 abrasive. (vertical scale $=20 \mu \mathrm{m}$, horizontal scale $=50 \mu \mathrm{m}$ )
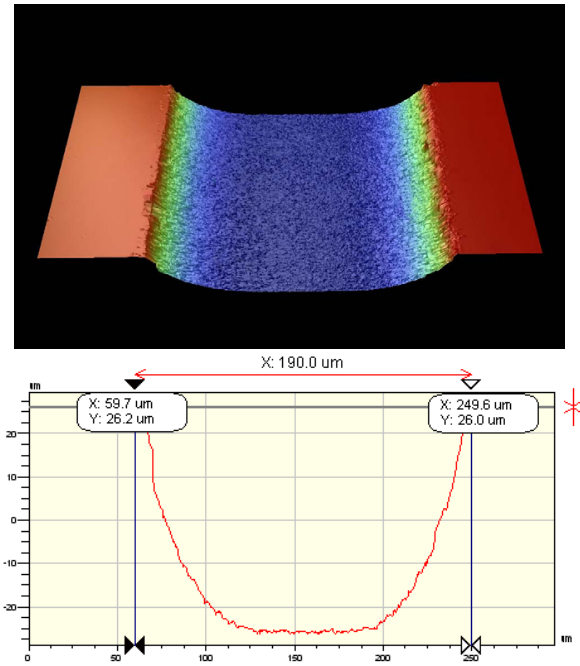

(a) Channel (20 scanning)
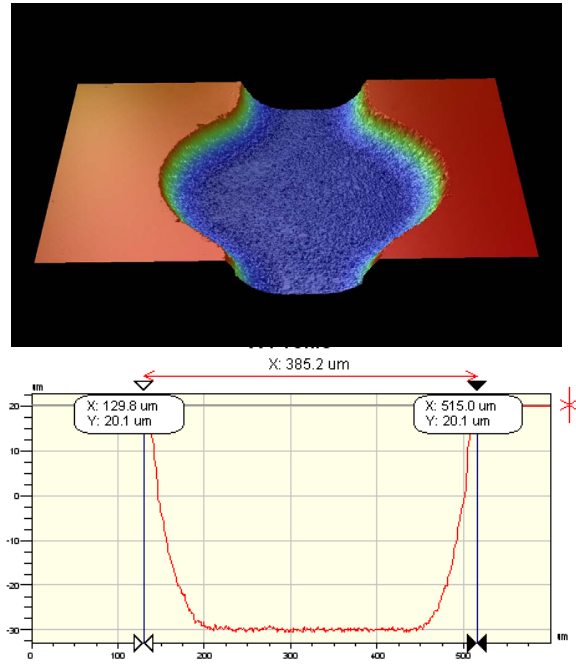

(b) Circle (20 scanning)
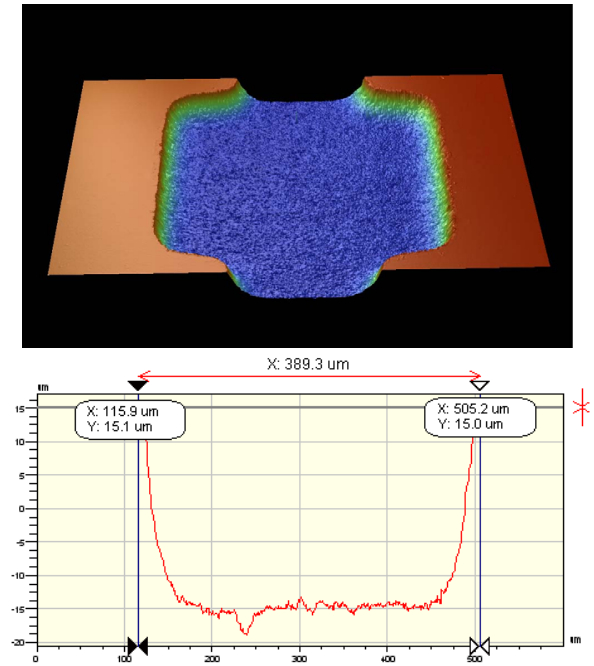

(c) Square (20 scanning)

Figure 7. 3-dimensional shapes and cross-sectional profiles of $200 \mu \mathrm{m}$ channels using WA\#1200 abrasive. (vertical scale $=20 \mu \mathrm{m}$, horizontal scale $=50 \mu \mathrm{m}$ )

Figures 8 and 9 show magnified top-view images of channels, square and circular patterns included in the $300 \mu \mathrm{m}$ channels, which are designed to simulate reservoirs in biochips. The images are obtained using 3D Micro-Vision System. Figure 10 shows machined shape variations according to increasing

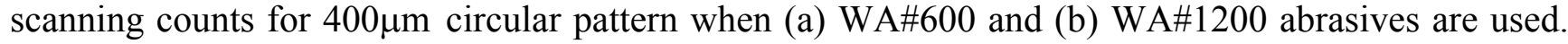
Measured machined depth and width variations of $200 \mu \mathrm{m}$ and $300 \mu \mathrm{m}$ channels are listed in Table 5 and 6, respectively. From these results, it can be seen that the machining capability of WA\#600 is higher than that of WA\#1200; the rate of the depth increase rises with increased scanning and abrasive size. Also, in Figure10, it can be observed that the machined width increases as scanning count 
increases. This is because the edges of used mask film (UV hardening polyurethane) are easily eroded by injected powder impact; thus, film thickness reduces rapidly, and top width of a channel increases during blasting.

Figure 11 shows machined depth variation according to increasing number of nozzle scanning for (a) $200 \mu \mathrm{m}$ and (b) $300 \mu \mathrm{m}$ channels, respectively. In the figure, it can be observed that the machined depth after 20th scan deviates a little from the linearity. This is due to the "blast lag effect", which is caused by the increase of particle impact angle to sidewall as masked line width increases. [10] The smaller the channel, the sooner this effect occurs. The top width of a channel increases during blasting, thus increasing rate of the erosion depth is accelerated.

Figure 12 shows the variation of the micro channel width for the (a) $200 \mu \mathrm{m}$ and (b) $300 \mu \mathrm{m}$ cases. From the figures, it can be observed that the machined depths and widths increase in proportion to the number of scanning.

Table 5. Depth variations according to the experimental conditions.

\begin{tabular}{ccccc}
\hline \multirow{2}{*}{$\begin{array}{c}\text { Scanning } \\
\text { counts }\end{array}$} & \multicolumn{2}{c}{$200 \mu \mathrm{m}$ channel } & \multicolumn{2}{c}{$300 \mu \mathrm{m}$ channel } \\
& WA\# 600 & WA\#1200 & WA\#600 & WA\#1200 \\
\hline 5 & 39.4 & 7.2 & 41.7 & 7.8 \\
10 & 77.3 & 15.8 & 82.5 & 15.1 \\
15 & 109.9 & 21 & 122 & 22 \\
20 & 176.6 & 52 & 199.6 & 49.1 \\
\hline
\end{tabular}

Table 6. Width variations according to the experimental conditions.

\begin{tabular}{ccccc}
\hline \multirow{2}{*}{$\begin{array}{c}\text { Scanning } \\
\text { counts }\end{array}$} & \multicolumn{2}{c}{$200 \mu \mathrm{m}$ channel } & \multicolumn{2}{c}{$300 \mu \mathrm{m}$ channel } \\
& WA\# 600 & WA\#1200 & WA\#600 & WA\#1200 \\
\hline 5 & 175.8 & 162.5 & 282.4 & 274.2 \\
10 & 193.2 & 174.2 & 295.5 & 280.8 \\
15 & 199.2 & 183.9 & 306.9 & 290.6 \\
20 & 206.5 & 190 & 318.3 & 299.5 \\
\hline
\end{tabular}

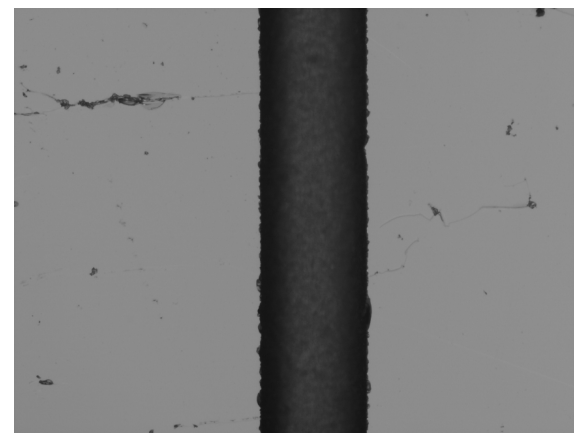

(a) Channel.

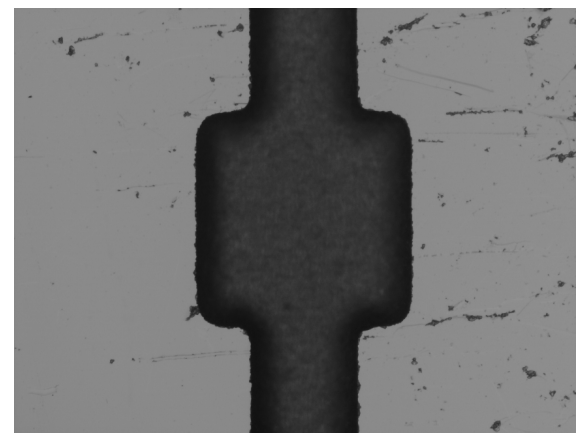

(b) Square.

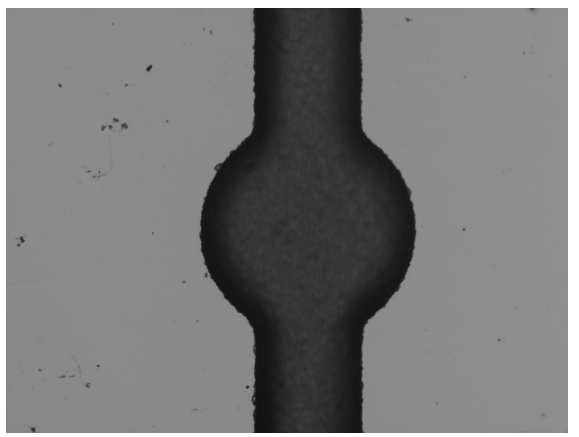

(c) Circle.

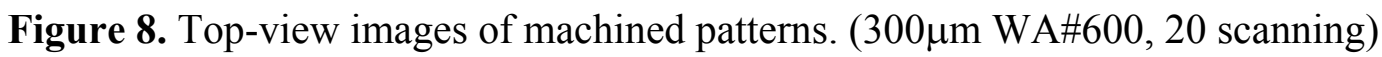




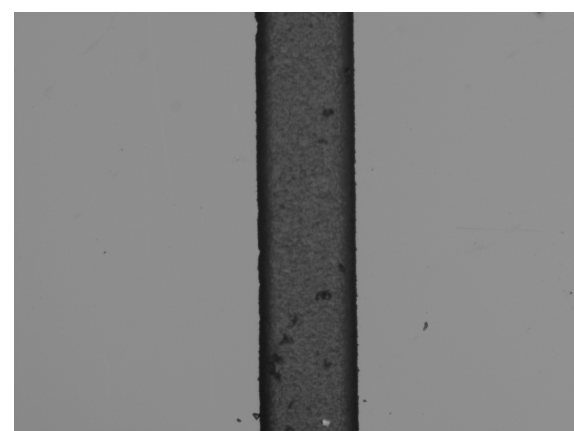

(a) Channel.

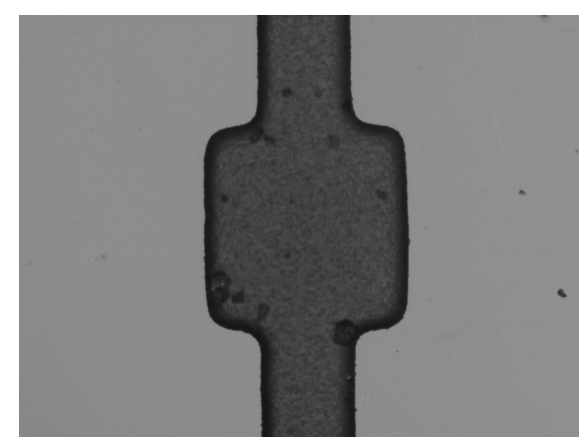

(b) Square.

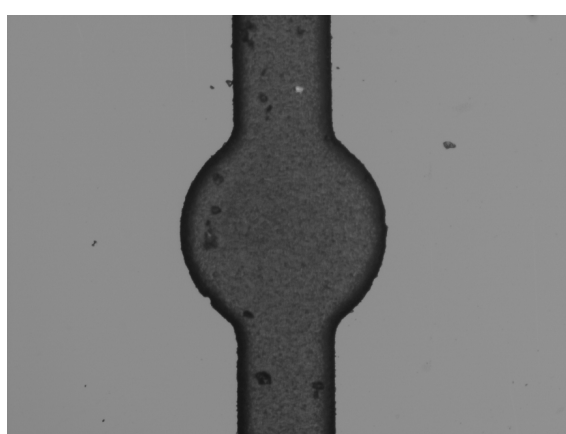

(c) Circle.

Figure 9. Top-view images of machined patterns. (300 $\mu \mathrm{m}$ WA\#1200, 20 scanning)
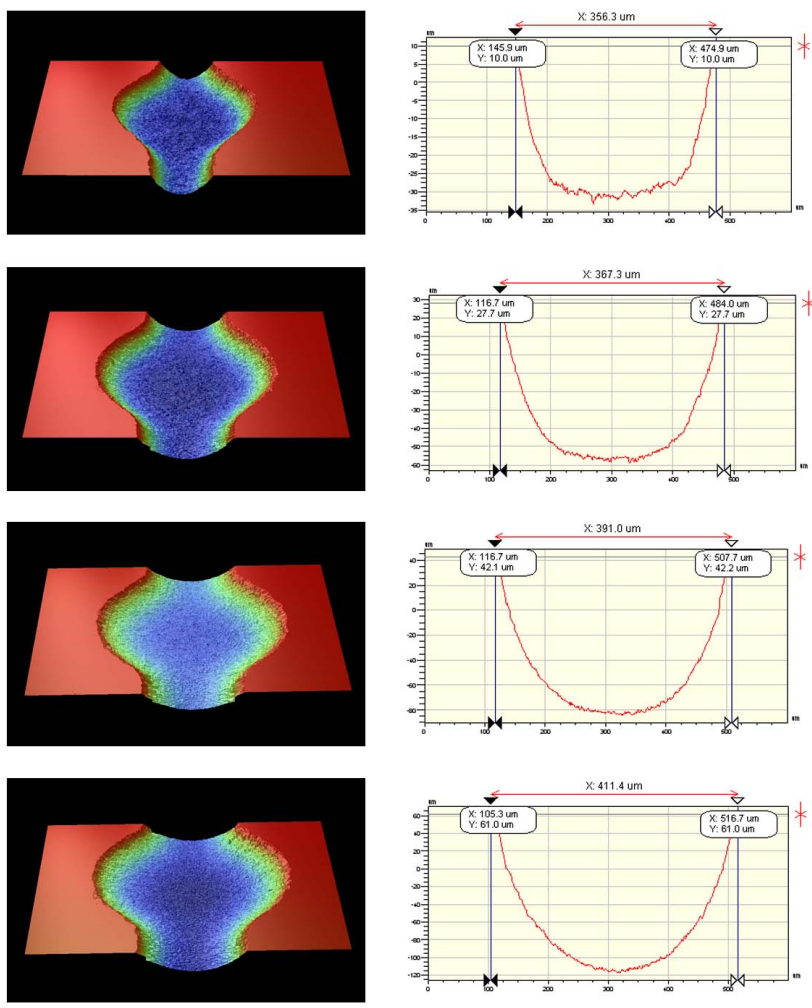

(a) WA\#600, 400 $\mu \mathrm{m}$ circular pattern
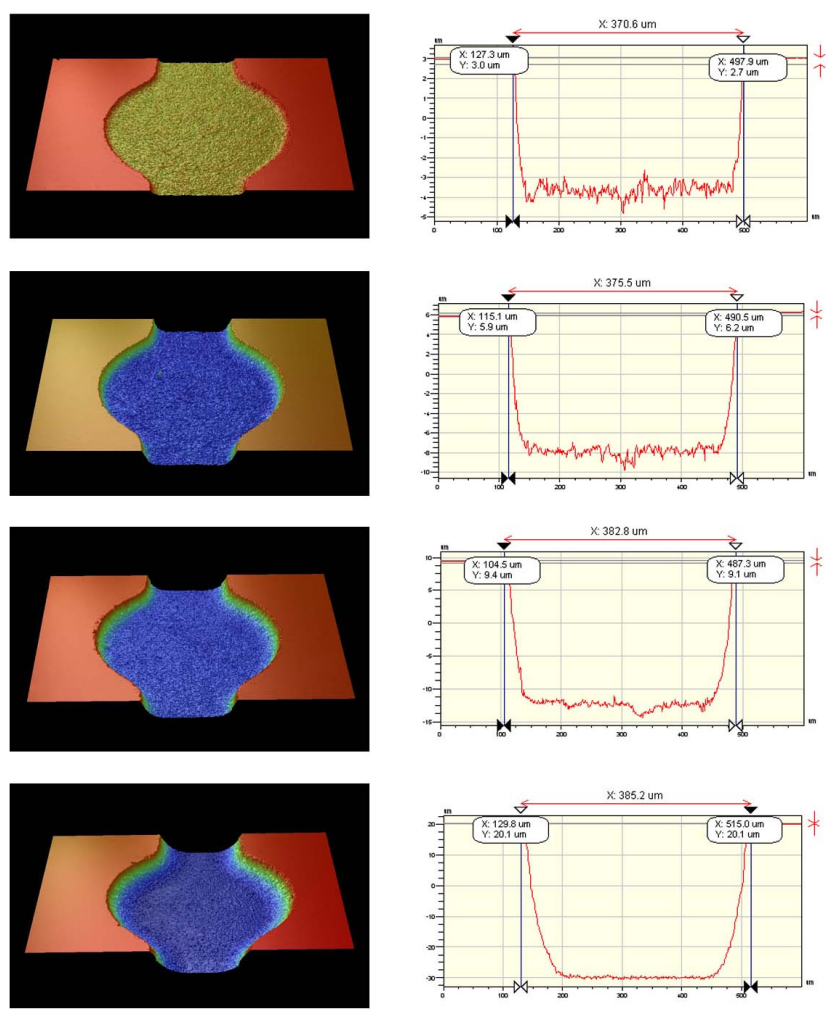

(b) WA\#1200, 400 $\mu \mathrm{m}$ circular pattern

Figure 10. Machined shape variations when nozzle scanning count is 5, 10, 15, 20. (vertical scale $=20 \mu \mathrm{m}$, horizontal scale $=50 \mu \mathrm{m}$ )

From the experimental results, it is found that the machined results vary with the imposed powder blasting process parameters such as abrasive particle size, number of nozzle scanning, etc. Thus, determination of optimum process conditions is very important when applying the powder blasting method to fabricate micro channels on fused silica glass. The experimental results in this study can be useful to achieve more satisfactory powder blasting results in related fields.

\section{Conclusions}

Through this experimental study to examine the effects of variation of process parameters on the characteristics of micro patterns machined in fused silica glass via a powder blasting process, the following conclusions can be obtained. 
(1) In the micro pattern masking process, masking errors of roughly $10 \mu \mathrm{m}$ were detected for all types of the designed channel width. For further research, more precise masking techniques should be applied.

(2) Overall, the measured micro channels show U-shape cross-sections due to the material removal characteristics of the applied powder blasting method. It was found that the machined depths increase in proportion to an increase of the number of nozzle scanning.

(3) Machined depths of circular and square type patterns increase in proportion to an increase of the number of nozzle scanning. It was found that more precise patterns could be obtained by increasing the number of nozzle scanning.

(4) The size of the employed abrasives, one of the process parameters in powder blasting, affects the machinability of the workpiece; larger abrasive size results in deeper and wider material removal, and a higher increasing rate of depth.

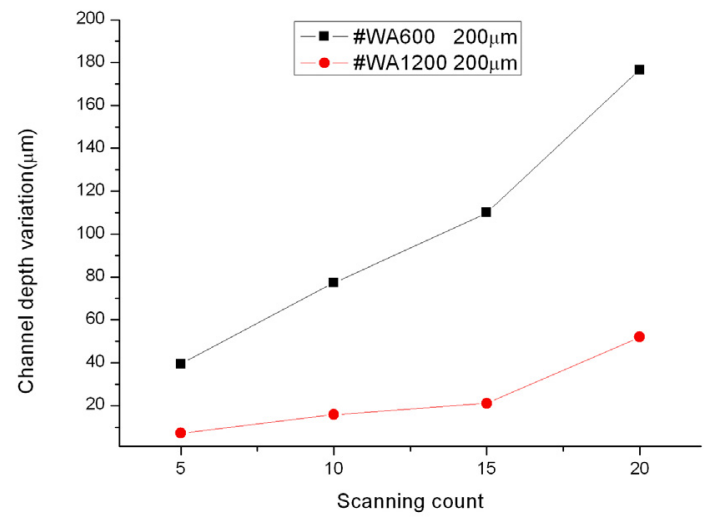

(a) $200 \mu \mathrm{m}$ channel

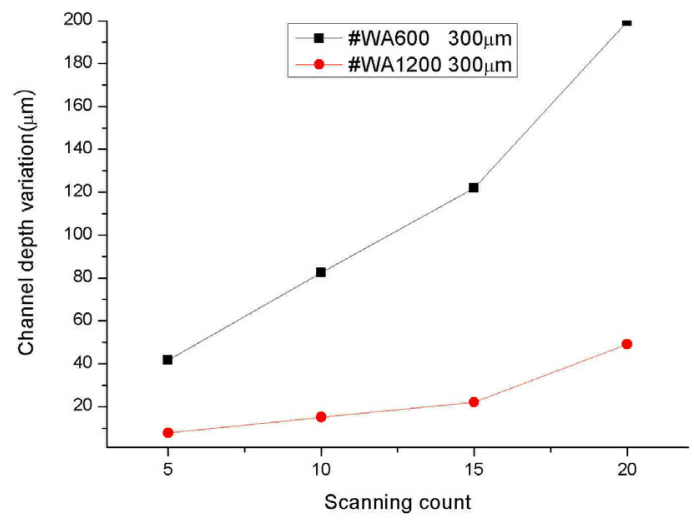

(b) $300 \mu \mathrm{m}$ channel

Figure 11. Channel depth variations according to the number of nozzle scanning.

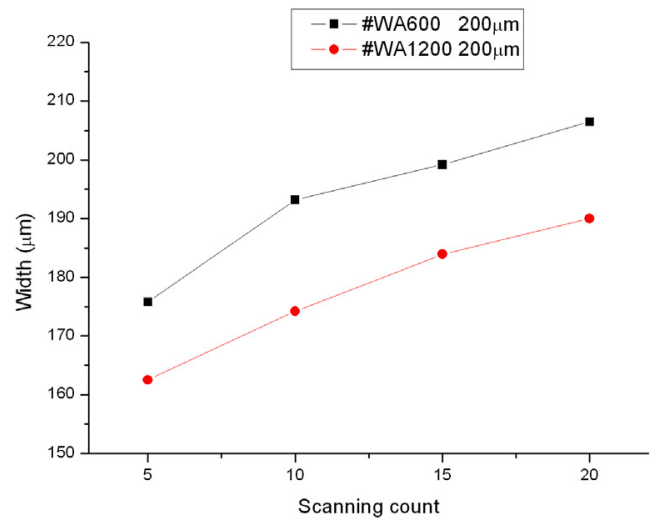

(a) $200 \mu \mathrm{m}$ channel

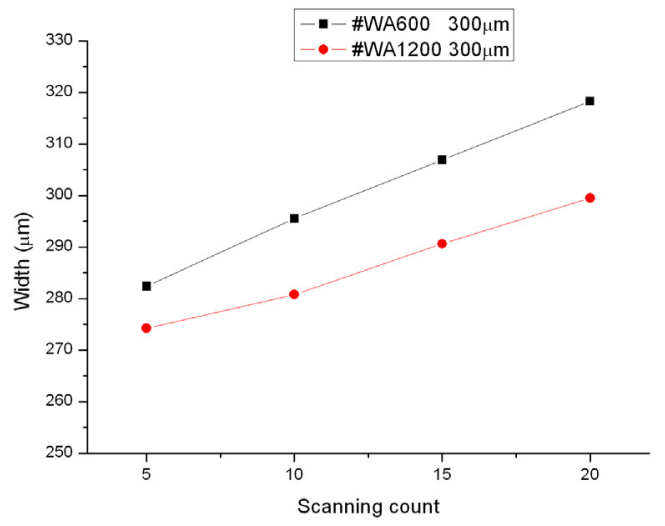

(b) $300 \mu \mathrm{m}$ channel

Figure 12. Channel width variations according to the number of nozzle scanning.

\section{Acknowledgement}

This work was supported by the University of Incheon Research Grant in 2007. 


\section{References}

1. Solignac, D.; Sayah, A.; Constantin, S.; Freitag, R.; Gijs, M.A.M. Powder blasting for the realisation of microchips for bio-analytic applications. Sensors and Actuators A 2001, 92, 388-393.

2. Yamazaki, Y. Application of MEMS technology to micro fuel cells. Electrochemica Acta 2004, 50, 663-666.

3. Mouradian, S. Lab-on-a-chip: Applications in proteomics. Current Opinion in Chemical Biology 2002, 6, 51-56.

4. Kricka, L.J. Microchips, microarrays, biochips and nanochips - personal laboratories for the $21 \mathrm{st}$ century. Clinica Chemica Acta 2001, 307, 219-223.

5. Belloy, E.; Thurre, S.; Walchiers, E.; Sayah, A.; Gijs, M.A.M. The introduction of powder blasting for sensor and microsystem applications. Sensors and Actuators 2000, 84, 330-337.

6. Yun, K.S.; Yoon, E. Microfabrication of 3-dimensional photoresist structures using selective patterning and development on two types of specific resists and its application to microfluidic components. In Proc. IEEE International conference on MEMS, 2004, pp. 757-760.

7. Tseng, F.G.; Chuang, Y.J.; Lin, W.K. A novel fabrication method of embedded micro channels employing simple UV dosage control and antireflection coating. In Proc. IEEE 15th International Conference in Micro Electro Mechanical Systems, 2002; pp. 69-75.

8. Roylance, A.M.; Angell, J.B. A batch-fabricated silicon accelerometer. In Proc. IEEE Transactions of Electron Devices, 1979; Vol. 8, pp. 1911-1917.

9. Slikkerveer, P.; Bouten, P.; de Haas, F. High quality mechanical etching of brittle materials by powder blasting. Sensors and Actuators A 2000, 85, 296-303.

10. Wensink, H.; Berenschot, J.W.; Jansen, H.V.; Elwenspoek, M.C. High resolution powder blast micromachining. In Proceedings of the IEEE Micro Electro Mechanical Systems, 2000; pp. 769774.

11. Park, D.S.; Yun, D.J.; Cho, M.W.; Shin, B.C. An Experimental Study on the Fabrication of Glassbased Acceleration Sensor Body Using Micro Powder Blasting Method. Sensors 2007, 7, 697-707.

12. Park, D.S.; Cho, M.W.; Lee, H.; Cho, W.S. Micro-grooving of glass using micro-abrasive jet machining. Journal of Materials Processing Technology 2004, 146, 234-240.

13. Park. D.S.; Cho, M.W.; Lee, H. Effects of the impact angle variations on the erosion rate of glass in powder blasting process. International Journal of Advanced Manufacturing Technology 2004, $23,444-450$.

(C) 2008 by MDPI (http://www.mdpi.org). Reproduction is permitted for noncommercial purposes. 